Authors' Contribution:

A Study Design

B Data Collection

C Statistical Analysis

D Data Interpretation

E Manuscript Preparation

F Literature Search

G Funds Collection

\section{The use of combination therapy in rehabilitation of patients with hip osteoarthritis - preliminary report}

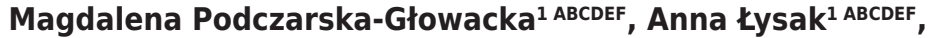 \\ Rafał Szulc-Cieplicki² BDFE \\ ${ }^{1}$ Chair of Physiotherapy, Gdansk University of Physical Education and Sport, Poland \\ ${ }^{2}$ Nadmorskie Medical Centre in Gdansk, Poland
}

abstract

Background

Material/Methods

Results

Conclusions

Key words

\section{article details}

Article statistics

Full-text PDF:

Copyright

Indexation:

Funding:

Conflict of interest: Corresponding author:

Open Access License:
The objective of the study was to assess the effectiveness of a 2-week therapeutic programme consisting of combination therapy and postisometric relaxation and its effect on the mobility of joints and the level of perception of pain in patients with osteoarthritis of hip joints.

The research was carried out on subjects clinically and radiologically diagnosed as patients with osteoarthritis of hip joints. 30 subjects, including 7 men and 23 women (average age of $67.8 \mathrm{yrs}$ ), underwent the examinations. The therapy lasted 2 weeks and consisted of 10 treatment sessions. The medical program included a combination therapy and individual exercises, i.e. postisometric relaxation of the hip joint. In the combination therapy conventional TENS and ultrasounds were applied. Moreover, tailored exercises were performed systematically every day at home.

The study proved that an individually prepared therapeutic program including postisometric relaxation and combination therapy improves ROM in all planes of hip joins in osteoarthritis. It was also stated that after 2 pain assessment tests (the VAS and Laitinen scales) the therapy was confirmed to be a successful method in pain relief. The researchers also noticed that systematically conducted therapy led to reducing the incidence of pain which is manifested by limitation of pharmacotherapy.

The research shows that combination therapy together with postisometric relaxation is an effective form of conservative treatment for degenerative changes in the hip joint.

degeneration changes of hip joints, combination therapy, postisometric relaxation, hip joint mobility, pain

Word count: 4,161; Tables: 1; Figures: 12; References: 28

Received: April 2015; Accepted: July 2015; Published: September 2015

http://www.balticsportscience.com

(๑) Gdansk University of Physical Education and Sport, Poland

AGRO, Celdes, CNKI Scholar (China National Knowledge Infrastructure), CNPIEC, De Gruyter - IBR (International Bibliography of Reviews of Scholarly Literature in the Humanities and Social Sciences), De Gruyter - IBZ (International Bibliography of Periodical Literature in the Humanities and Social Sciences), DOAJ, EBSCO - Central \& Eastern European Academic Source, EBSCO - SPORTDiscus, EBSCO Discovery Service, Google Scholar, Index Copernicus, J-Gate, Naviga (Softweco, Primo Central (ExLibris), ProQuest - Family Health, ProQuest - Health \& Medical Complete, ProQuest - Illustrata: Health Sciences, ProQuest - Nursing \& Allied Health Source, Summon (Serials Solutions/ProQuest, TDOne (TDNet), Ulrich's Periodicals Directory/ulrichsweb, WorldCat (OCLC)

This research received no specific grant from any funding agency in the public, commercial, or not-for-profit sectors.

Authors have declared that no competing interest exists.

Dr Magdalena Podczarska-Glowacka, Chair of Physiotherapy, Gdansk University of Physical Education and Sport, Kazimierza Gorskiego 1 Str., 80-331 Gdansk, Poland; phone no. +48 585547182 ;

e-mail magdapodczarska@awf.gda.pl

This is an open access article distributed under the terms of the Creative Commons Attribution-Non-commercial 4.0 International (http://creativecommons.org/licenses/by-nc/4.0/), which permits use, distribution, and reproduction in any medium, provided the original work is properly cited, the use is non-commercial and is otherwise in compliance with the license. 


\section{INTRODUCTION}

Osteoarthritis of joints (OA), including hip joints, is currently one of the biggest health and economic problems not only in Poland but in the world as well [1]. The hip, which undergoes a process of degeneration more often than other joints, is casually associated with substantial dynamic and static loads of its elements [1, 2]. The disease examined from the epidemiological and social points of view, in the assessment of WHO has been classified into a group of chronic diseases, so-called civilization diseases [3].

Epidemiological studies show that in Poland 8 million people suffer from distorting degenerative changes, and approximately $40 \%$ have degenerative changes in the hip joints [4]. The hip osteoarthritis usually develops in people aged over 50 years, often as a consequence of the natural wear and tear of the elements forming the structure of the joint. In the last two decades the age of the population with the upward trend of clinical and radiographic symptoms of this disease has been lowered [5].

Hip osteoarthritis is characterized by a slow, progressive and degenerative process, damaging the articular cartilage and its surface, sensitive to increased and unbalanced loads [6]. The statement "sick hip is a sick man" becomes a legitimate expression along with the progression of the disease. The most common symptom that accompanies degenerative changes is pain, located in the groin area and buttocks, often radiating to the thigh and the knee $[4,5]$. Initially, it is an exertion pain, but with the development of the disease it also occurs at rest. Muscle weakness and persistent pain restrict the mobility of internal rotation, abduction and extension of joints. As a consequence, a deterioration of locomotion and limping occur, which limit the ability to work thus worsening the quality of life of people with hip osteoarthritis $[4,5,7]$.

Drug-free treatment involves procedures taking into account patients' education, physio therapy, physical therapy and soft tissue techniques, as well as appropriate use of orthopedic supplies and assistive devices [1, 8]. A decrease in pain is a basis for therapeutic intervention enabling participation in further treatment which leads to the improvement in functional activities [9]. Therefore, appropriately selected mobilization and manipulation of joints and exercise therapy, as well as passive exercises focused on temporarily reducing the pain level, physical therapy methods, including among others, transcutaneous electrical nerve stimulation (TENS) or the ultrasound method (UD), are believed to be optimal operations [10, 11]. The studies emphasize a particular importance of physiotherapy as a very effective and relatively inexpensive form of therapy to relieve and/or control pain in osteoarthritis [12]. Other authors pay attention to the need of further, high quality research in order to establish an optimal and effective therapeutic dose [13]. Achieving an analgesic effect after an application of physical factors enables improving the facilitation of muscles, which gives a possibility to generate greater muscle strength during isokinetic exercises [14]. Osteo- and arthrokinematic changes in joints progressing with age and intensification of degenerative changes show some general trends, including for example a gradual limitation of the range of motion (ROM) $[15,16]$. There are many scientific studies determining the range of motion of lower limbs joints [17]. In much research it was proved that applicable 
in pain control and appropriately selected therapeutic exercises, manipulation and mobilization can reverse the decreasing trend of joints mobility. In addition, combining the above mentioned techniques with stretching exercises may result in the improvement in joint dysfunctions in patients with hip osteoarthritis [10]. Meta-analysis which was published in 2009 showed a good (B) level of the strength of the evidence of the efficacy of therapeutic exercises and manipulation in the treatment of degenerative changes in the knee joint, and a limited (C) level of the strength of the evidence of the efficacy of therapeutic exercises and manual therapy in the treatment of hip osteoarthritis [18].

The aim of this study was to evaluate the effectiveness of combination therapy treatments and postisometric relaxation proposed in a 2-week treatment program directed at patients with hip osteoarthritis (OA).

\section{MATERIALS AND METHODS}

A total of 30 patients ( 7 men and 23 women) clinically and radio logically diagnosed with hip osteoarthritis were enrolled in the study. At the beginning of the therapeutic program, treated as a pilot program, the average age of all subjects was 67.8 years (SD 6.65) (Table 1). The subjects were qualified by a physician, specialist in medical rehabilitation. The level of degenerative changes was assessed by the Altman scale and a specialist in radiology and diagnostic imaging. The selection of groups was deliberate and included the following criteria: clinical and radiological diagnosed hip osteoarthritis of a joint or joints, morning stiffness, a signed consent to participate in the research and pharmacological treatment of a fixed constant amount of drug during the therapy. Exclusion criteria included patients after hip replacement surgery, intra-articular or other systemic steroid received in the last month.

Table 1. Characteristics of the research group

\begin{tabular}{|c|c|c|c|}
\hline \multirow{2}{*}{ Sex } & \multirow{2}{*}{ Number } & \multicolumn{2}{|c|}{ Age } \\
\hline & & min.-max. & $\overline{\mathrm{x}} \pm \mathrm{SD}$ \\
\hline W & 23 & $51-80$ & $67.04 \pm 7.02$ \\
\hline$M$ & 7 & $65-79$ & $70.3 \pm 4.9$ \\
\hline Total & 30 & $51-80$ & $67.8 \pm 6.65$ \\
\hline
\end{tabular}

To assess the degree of pain severity, two pain subjective scales were used: the visual-analogue scale VAS and the Laitinen scale [19, 20]. The severity of pain was measured twice, before and after the treatment. Subjective pain severity was determined by the visual-analogue scale VAS usually 10 centimeters in length. At the beginning of the line a score of 0 meant no pain, while at the end it was the worst perceptible or imaginable pain, i.e. the pain maximum. The score in the range of 1-3 determined the pain as weak, 4-7 as moderate, from 8-10 as very severe. The subjects described the severity of their own symptoms in the proper sequence. The second subjective pain scale was the Laitinen questionnaire, in which the patient marked on a five-point scale the most "current" pain severity [20]. The measurement of mobility was made twice before and after the therapy in three planes of motion: the sagittal (flexion and extension), the front (abduction and adduction) and the transverse (external and internal rotation) ones. Starting positions for the measurement of 
mobility have been selected in accordance with the ISOM-SFTR methodology (Eng. International SFTR Method of Measuring and Recording Joint Motion, the International Standard Orthopaedic Measurements ) [21]. A goniometer was used for measurements.

A therapeutic procedure (a combination therapy and individual exercises) consisted of 10 treatment sessions in an outpatient setting. The time of each session was similar and lasted about 40 minutes each (real time treatment, which did not include preparation time). Each subject underwent a tailored therapeutic program involving a combination therapy (TENS + UD) and individual exercises, i.e. postisometric relaxation of the hip. The combination therapy (TENS + UD) was performed with an UltraMARP D89 device, which allowed a simultaneous application of an ultrasound (UD) wave and impulsive alternating current. The following treatment parameters were used: conventional TENS (pulse duration - 100us, frequency of rhythm of 80-100 [Hz], ultrasounds (pulse wave, $0.8\left[\mathrm{~W} / \mathrm{cm}^{2}\right]$ and a fill factor $(50 \%)$. The combination therapy (TENS + UD) was performed in the lying position. An active electrode was connected to the ultrasound head, the negative pole (cathode). A passive electrode (anode) was a lamellar electrode closing a circuit. The lamellar electrode was placed para spinal on the height of the lumbar spine, on the same side as the degenerative hip. In consistence with the methodology of electrotherapy, a wet prime was placed under the lamellar electrode. The procedure of the combination therapy was performed by an active electrode (ultrasound head), a dynamic method, where the field treatment was the damaged hip (around the greater tro-chanter). The duration of a single treatment in the combination therapy (TENS + UD) was 8 minutes. Postisometric relaxation for the flexor, extensor, abductor, and adductor, internal and ex-ternal rotators was applied. The therapy for the aforementioned muscles was conducted on an individual basis according to the methodology proposed by Rakowski [22]. Postisometric relaxation was performed periodically, where one cycle consisted of three phases. During the first phase muscle stretching lasted up to a slight pain sensation or until a feeling of slight stretching of the exercised muscle or muscle groups were observed. The second phase was isometric muscle tension which lasted 8-10 seconds, and was then followed by the third stage. In the third phase complete relaxation of the muscles took place followed by re-stretching of the exercised muscle group. The whole cycle was repeated from 3 to 5 times.

In addition, the treatment was enriched with a tailored set of exercises performed at home. The training was aimed, in addition to educational values, at making the subjects aware of the need to continue therapeutic exercises in the further health improving process. The authors of the article also cared for a patient who after completing a 10-treatment program could perform the same set of therapeutic exercises at home.

Data were analyzed using the statistical software, Statistica version 10.0. The Student's t-test for dependent variables or non-parametric Wilcoxon test were used to analyze bound variables. Statistical significance was set at $\mathrm{p}<0.05$. 


\section{RESULTS}

Results of the analysis showed a significant increase in the value of the variable measuring hip flexion after the treatment compared to the state before the treatment $(\mathrm{p}=0.0000)$. The mean value of hip flexion was 59 degrees with the standard deviation of 12.4. However, after the combination therapy with postisometric relaxation the mean value of flexion increased to $71 \pm 16.4$ degrees (Fig. 1.).

The mean value of hip extension before the treatment was $6.8 \pm 1.2$ degrees. After physiotherapy in the form of the combination therapy and kinesiotherapy, the mean value of extension improved by 2.5 degrees (Fig. 2). Results of the analysis showed a significant increase in the value of the variable measuring hip extension after the treatment compared to the state before the treatment $(\mathrm{p}=0.0000)$.

Results of the analysis showed a significant increase in the value of the variable measuring hip abduction after the treatment compared to the state before the treatment ( $\mathrm{p}=0.0000)$. After the combination therapy, along with postisometric relaxation, the mean value of hip abduction in patients with osteoarthritis improved from $17.0 \pm 2.9$ degrees to $23.0 \pm 4.1$ degrees (Fig. 3).

The mean value of hip adduction before the treatment was $18.1 \pm 4.6$ degrees. After the combination therapy with kinesitherapy, the mean value of adduction increased to $23.5 \pm 5.1$ degrees (Fig. 4). Results of the analysis showed a significant increase in the value of the variable measuring hip adduction after the treatment compared to the state before the treatment $(p=0.0000)$.

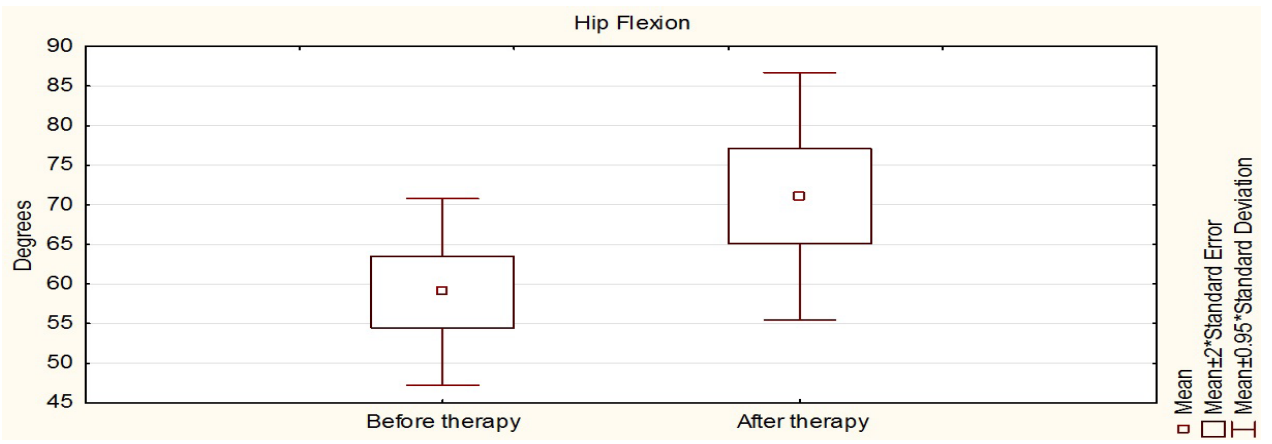

Fig 1 . The mean values of the variable measuring hip flexion before and after the therapy

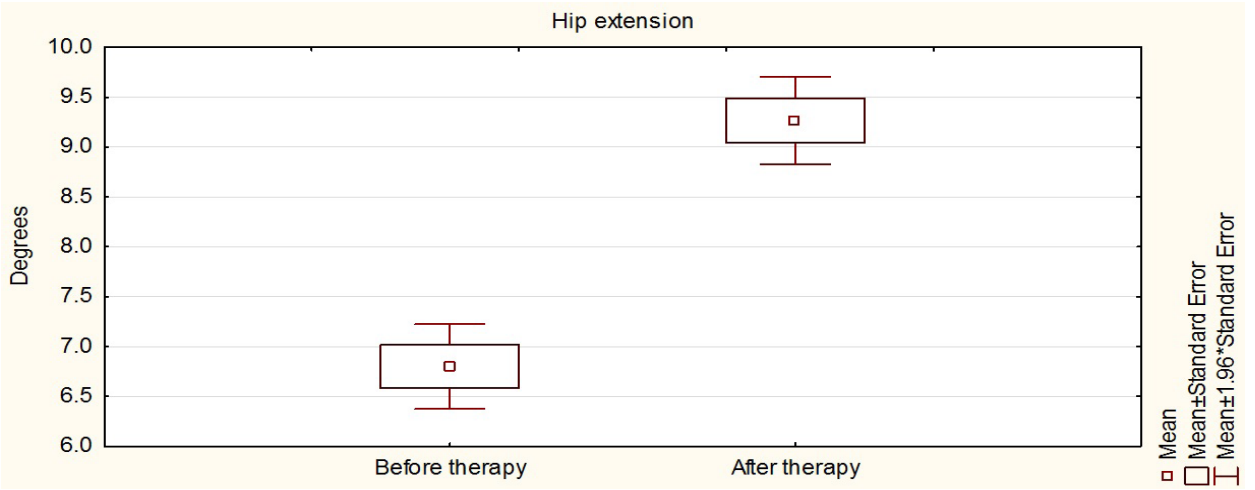

Fig 2. The mean values of the variable measuring hip extension before and after the therapy 


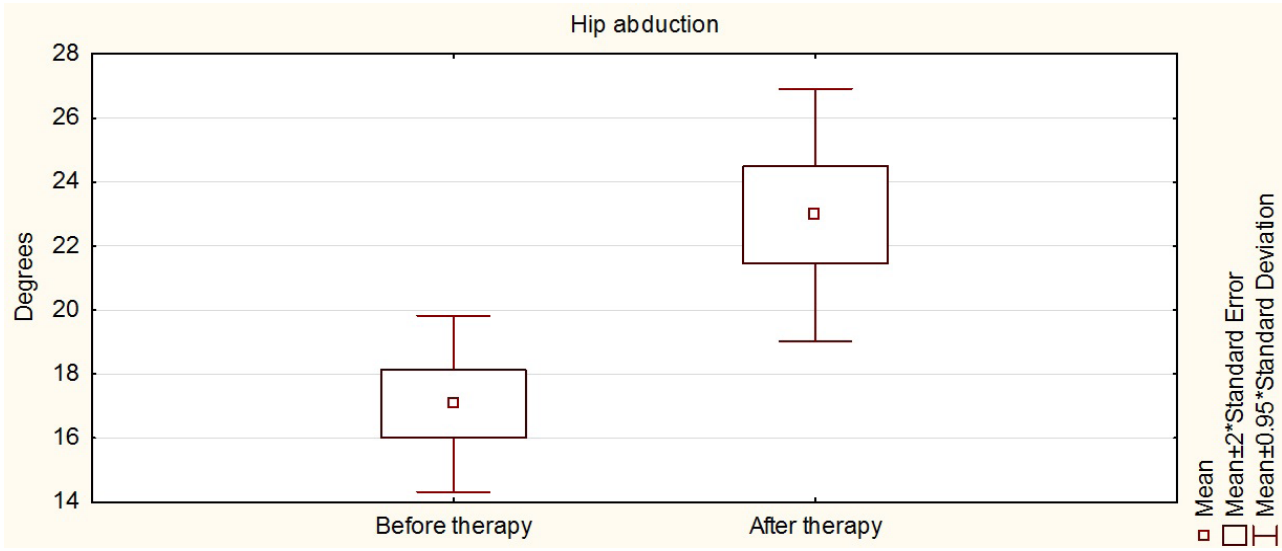

Fig 3. The mean values of the variable measuring hip abduction before and after the therapy

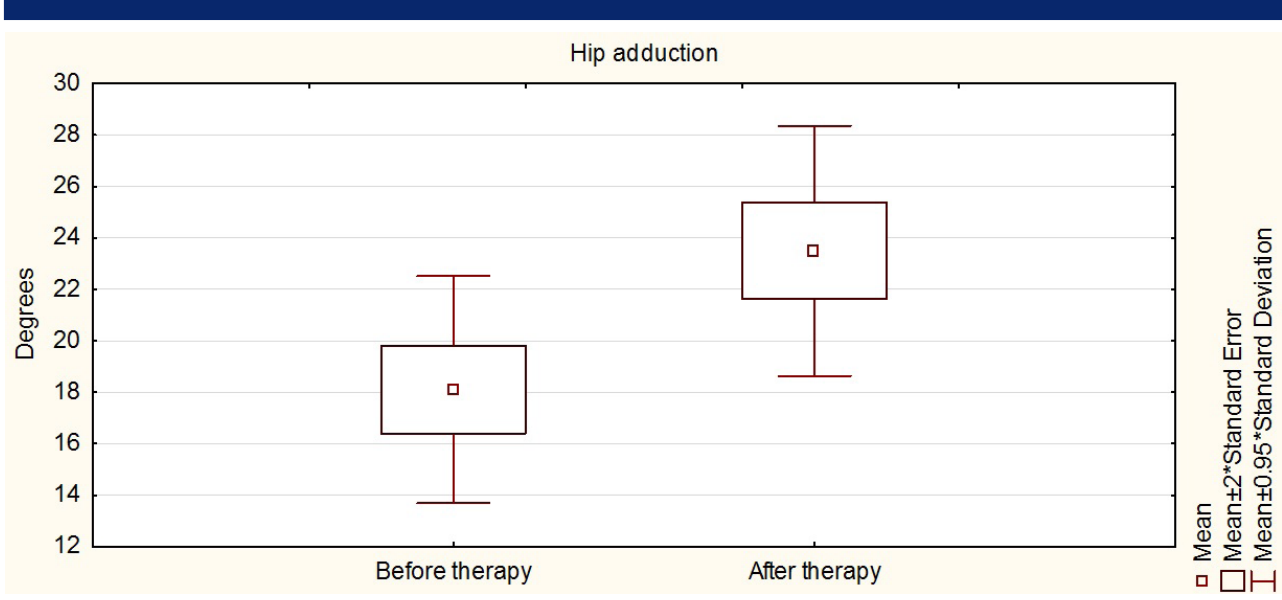

Fig 4. The mean values of the variable measuring hip adduction before and after the therapy

The mean value of hip external rotation before the treatment was $28.2 \pm 2.9$ degrees. However, after the combination therapy with postisometric relaxation the mean value of hip external rotation has risen to $32.4 \pm 2.7$ degrees (Fig. 5). The results of the analysis showed a significant increase in the variable measuring hip external rotation after the treatment compared to the state before the treatment $(\mathrm{p}=0.0000)$.

The mean value of the hip internal rotation before the treatment was $24.1 \pm 4.9$ degrees. However, after the combination therapy with postisometric relaxation the mean value of hip internal rotation increased to $28.6 \pm 5.3$ degrees (Fig. 6 ). The results of the analysis showed a significant increase in the variable hip internal rotation after the therapy compared to the state before the treatment $(\mathrm{p}=0.0000)$.

Results of the analysis showed a significant decrease in the value of the variable measuring pain according to VAS after the treatment compared to the situation before the treatment $(p=0.0000)$. The assessment of pain severity was determined by the visual-analogue VAS scale before and after the therapy. The mean value of pain severity before the therapy was $5.5 \pm 1.7$ points, while after the combination therapy and postisometric relaxation the mean value decreased to $3.3 \pm 1.6$ points (Fig. 7). 
Results of the analysis showed a significant decrease in the value of the variable on the Laitinen scale (total score) after the treatment compared to the state before the treatment $(\mathrm{p}=0.0000)$. The mean value of points according to the Laitinen scale before the treatment was $6.2 \pm 2.1$, while after the combination therapy and postisometric relaxation the mean value of points according to the Laitinen scale (total score) was reduced to $3.7 \pm 2.1$ (Fig. 8). The lowered values in the Laitinen scale were found in 28 subjects; in 2 patients no improvement was observed. The tested variable was assessed before and after the therapy.

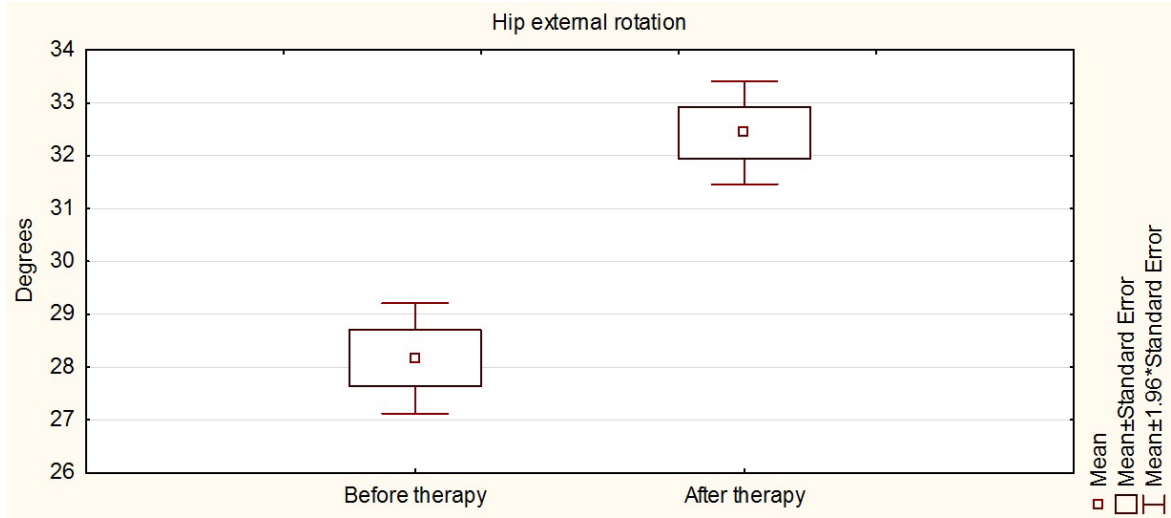

Fig 5. The mean values of the variable measuring hip adduction before and after the therapy

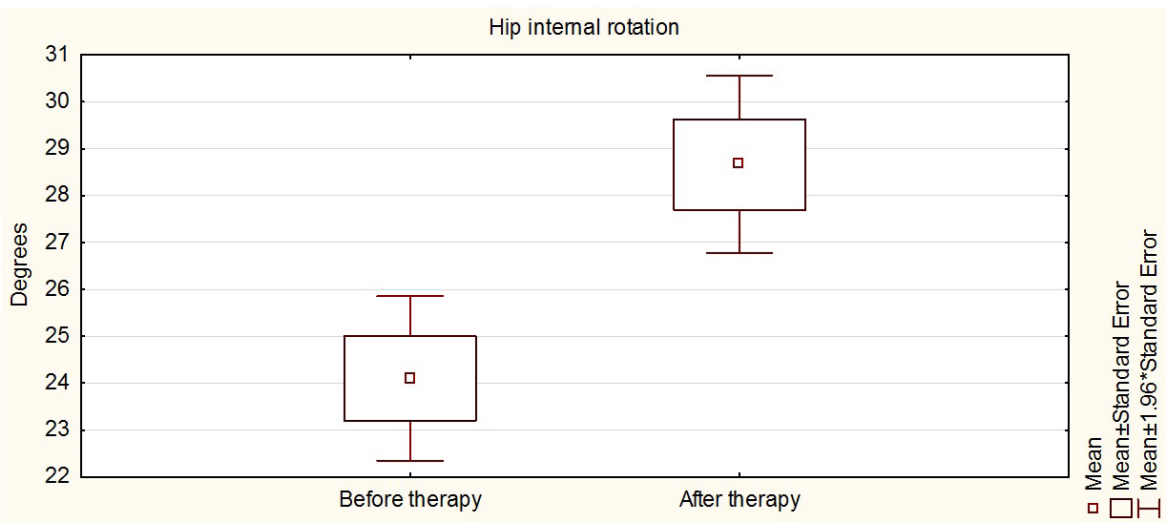

Fig 6. The mean values of the variable measuring hip internal rotation before and after therapy

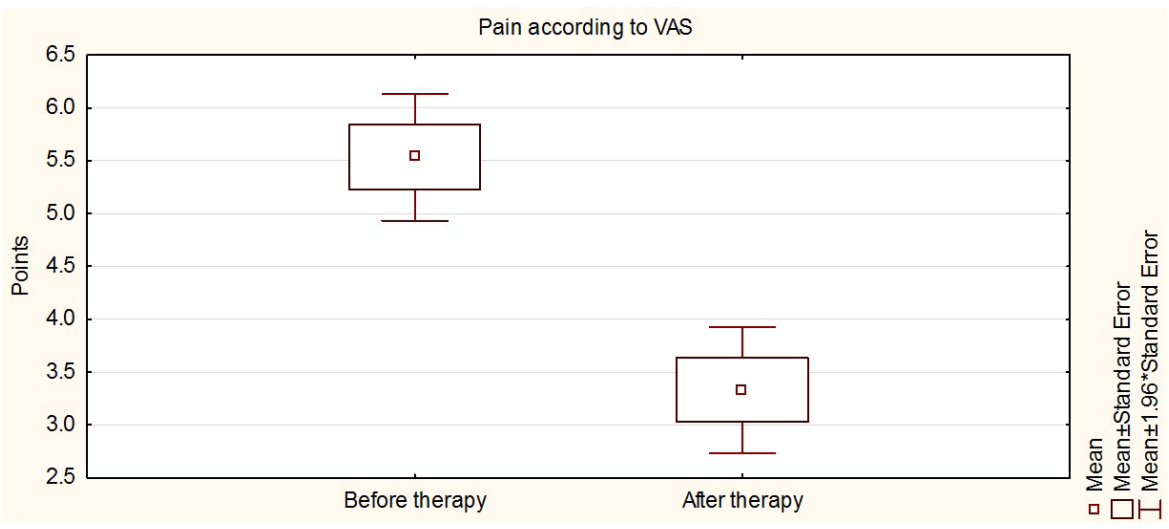

Fig 7. The mean values of the variable measuring pain according to VAS before and after therapy 


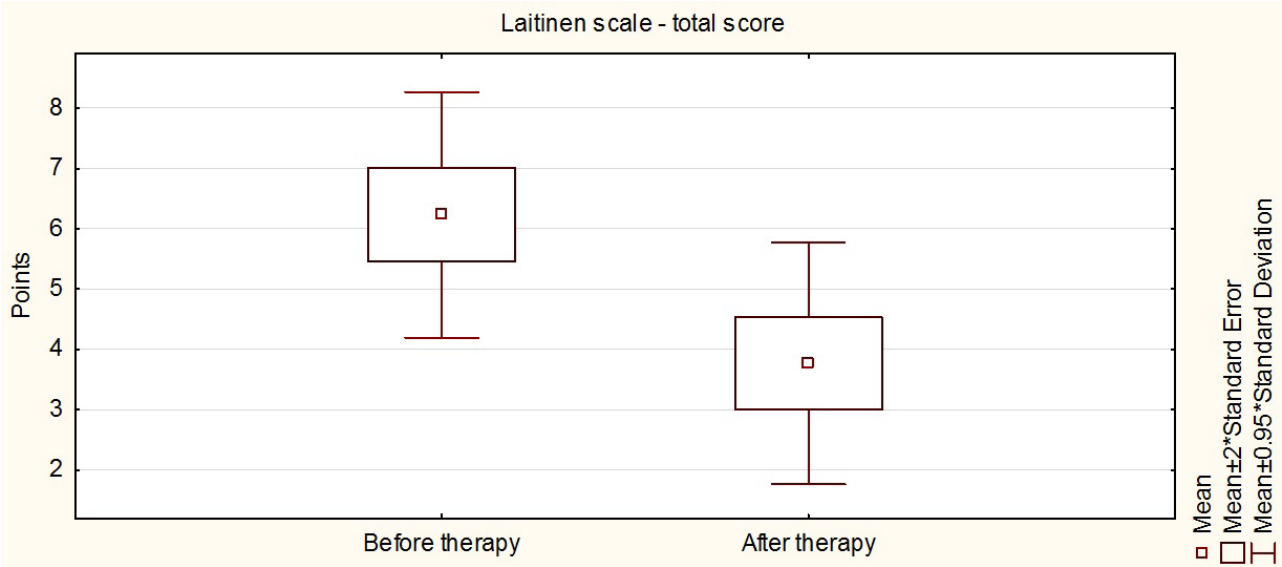

Fig 8. The mean values of the variable on the Laitien scale (total score) before and after the therapy

Results of the analysis showed a significant decrease in the value of the variable measuring pain severity on the Laitinen scale after the treatment compared to the state before the treatment $(p=0.0000)$. The mean value of points on the Laitinen scale before the treatment was $2.1 \pm 0.7$, while after the combination therapy together with postisometric relaxation the mean value of points on the Laitinen scale measuring pain severity was reduced to 1.3 \pm 0.7 (Fig. 9). In 24 patients the pain was reduced; 6 patients reported the pain severity the same as before the therapy.

For the variable measuring the frequency of pain on the Laitinen scale the results of the analysis showed a significant decrease after the treatment compared to the state before the treatment $(p=0.0000)$. The mean value of points on the Laitinen scale before the treatment was $2.2 \pm 0.7$, while after the application of the combination therapy and postisometric relaxation the mean value of points decreased to $1.4 \pm 0.7$ (Fig. 10). In 19 patients a reduction in the frequency of pain was observed, 11 patients rated it as the same before and after the treatment.

Results of the analysis showed a significant decrease in the value of the variable testing the use of painkillers and anti-inflammatory drugs on the Laitinen scale after the treatment com-pared to the situation before the treatment ( $p$ $=0.0000$ ). The mean value of points on the Laitinen scale before the treatment was $1.5 \pm 0.7$, while after the combination therapy in conjunction with postisometric relaxation the mean value of points on the Laitinen scale - the use of painkillers and anti-inflammatory drugs - decreased to $0.7 \pm 0.5$ (Fig. 11). In 22 patients there were reductions in the use of pharmacotherapy; 8 patients rated the test variable just the same before and after the therapy.

For the variable measuring limited mobility on the Laitinen scale scores after the therapy did not change. All patients reported mobility being at the same level before and after the therapy. 


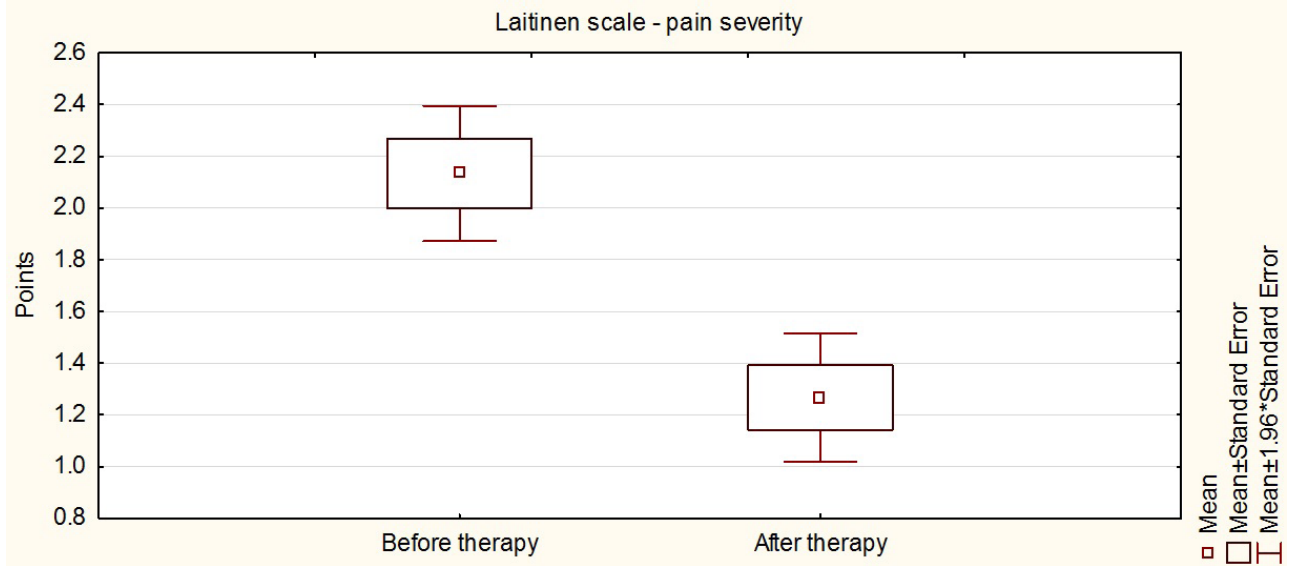

Fig 9. The mean values of the variable measuring pain severity on the Laitinen scale before and after the therapy

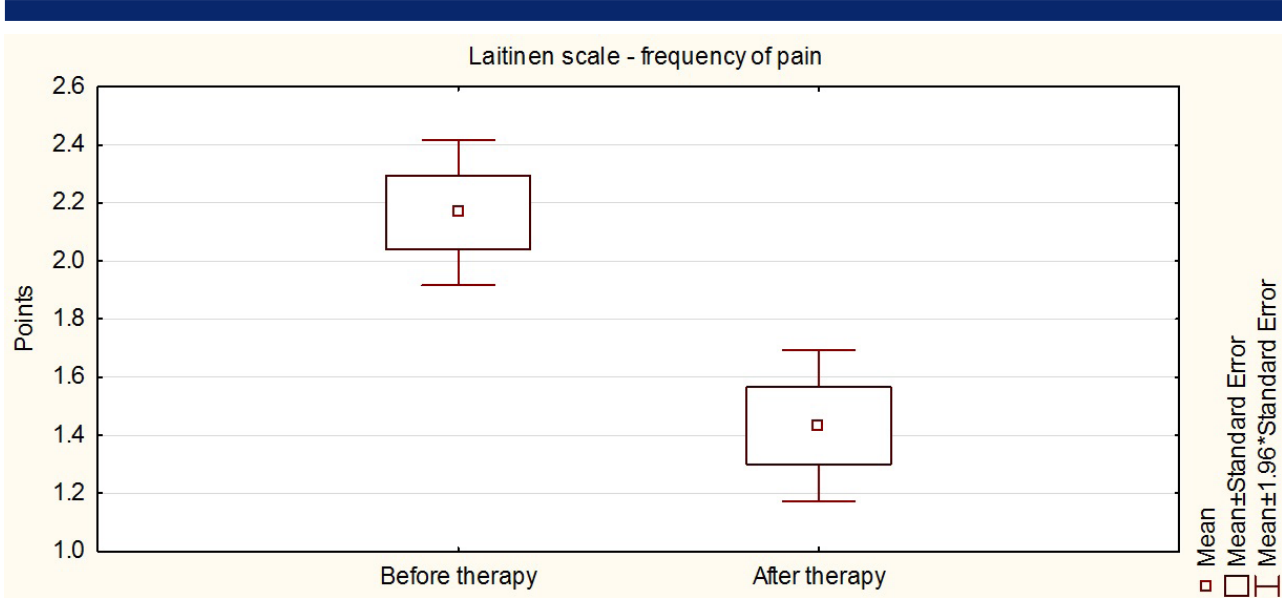

Fig 10. The mean values of the variable measuring the frequency of pain on the Laitinen scale before and after the therapy

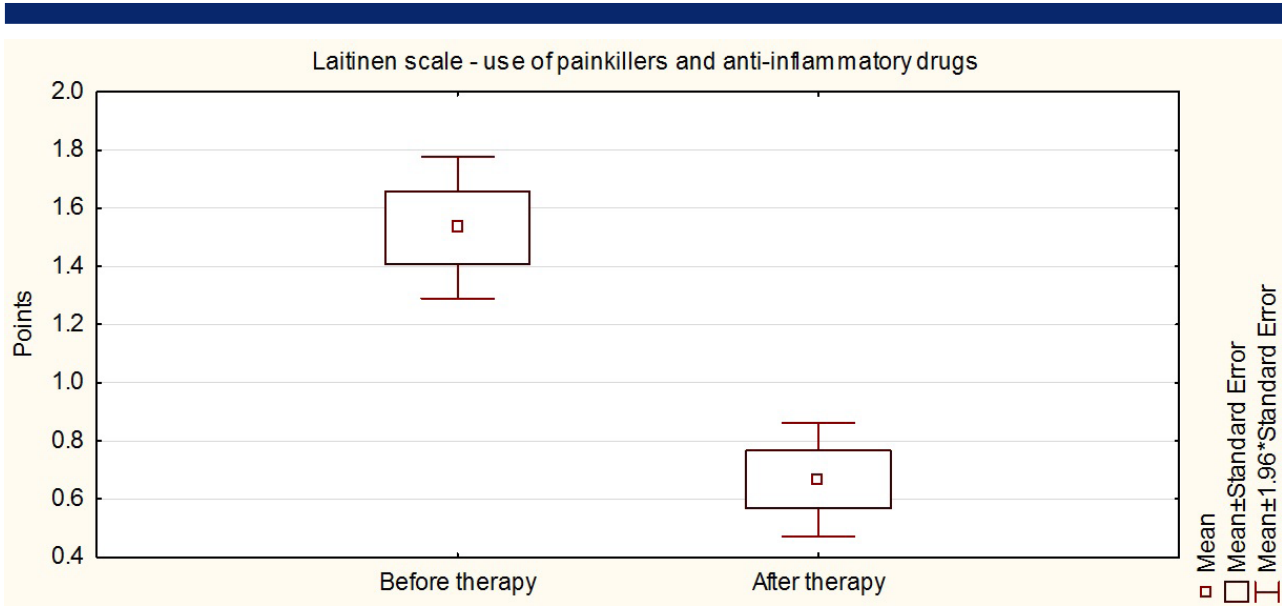

Fig 11. The mean values of the variable testing the use of painkillers and anti-inflammatory drugs on the Laitinen scale before and after the therapy. 


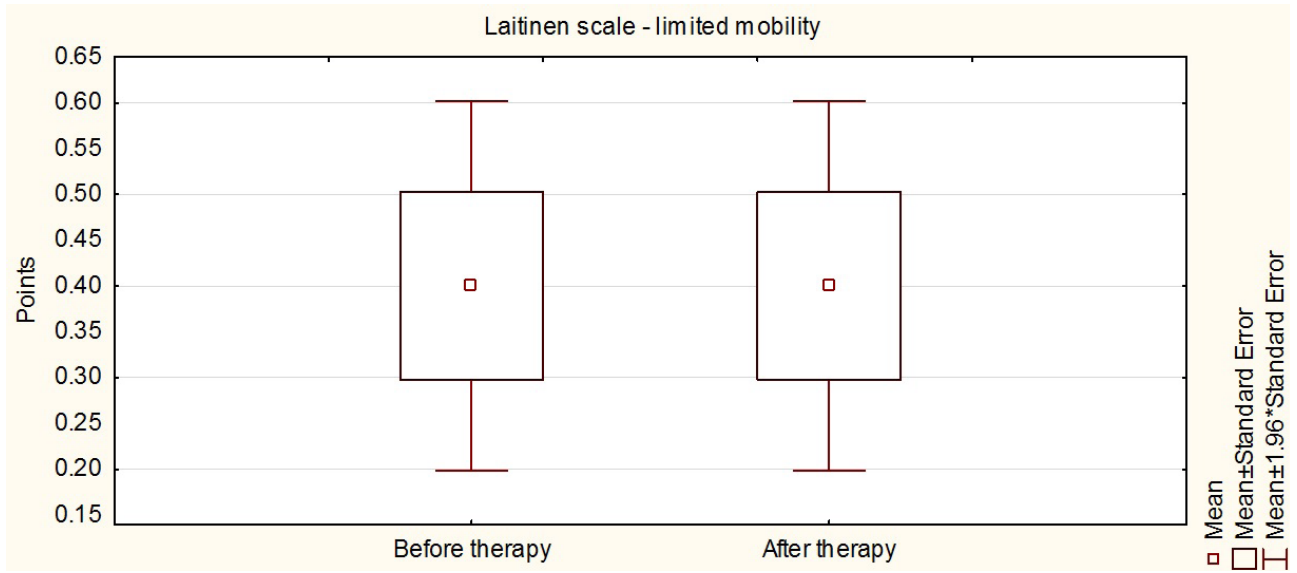

Fig 12. The mean values of the variable measuring limited mobility before and after the therapy

\section{DISCUSSION}

In the available source material the importance of conservative rehabilitation covering physiotherapy and kinesiotherapy in hip osteoarthritis is emphasized. It also draws attention to permanent search for proper and tailored therapeutic programs [23, 24, 25].

The authors' own research on hip mobility showed a significant improvement in all planes of motion after the implementation of postisometric relaxation and combination therapy (TENS + UD) in hip osteoarthritis. Hoeksma et al. [10], who compared postisometric relaxation with traditional active exercises against gravity in hip osteoarthritis, obtained greater effectiveness of the applied manual therapy over active exercises in the improvement of mobility as well as a decrease in pain. Taradaj et al. [26] claimed that the combination therapy (TENS + UD) might be regarded as an effective pain therapy allowing application of tailored electric stimulus - conventional TENS within the field treatment. The authors' own research converges with the observations of the above cited researchers. Khadilka et al. [27] testing the effect of electrotherapy in the form of transcutaneous electrical stimulation of nerves in chronic spine pains indicated the need for further, high quality, random scientific research with particular emphasis on benefits and risks of long-lasting application of treatments. The authors of this study also suggest verification of the effectiveness of the therapy through objective and carried out on a large population research, although their own works had only a pilot character. French et al. [28] present a similar opinion. They suggest comparing the effects of the applied treatments in patients with hip osteoarthritis in the experiment carried out on big samples (50 persons) randomly assigned to experiment groups in which the therapy should have 6-8 treatment sessions and last 8 weeks. Certin et al. [14], who analyzed the effect of physical factors such as transcutaneous electrical stimulation of nerves, ultrasonotherapy and short-wave diathermy applied before isokinetic exercises, reported larger analgesic effectiveness and functional improvement in the tested subjects who used transcutaneous electrical stimulation of nerves.

According to the authors of this study, ambulatory therapy is not sufficient enough, so they decided to broaden it with an instruction of individualized 
exercises to be performed at home. The purpose of autotherapy was not only to widen the scope of exercises but to alert the patient's own responsibility for the further therapeutic process. Van Es et al. [12] also understand the need of autotherapy as a key element in the process of medical improvement, while reserving the possibility of physiotherapeutic control at home.

The authors own pilot research as well as many works of the above cited authors indicate the appropriateness and the effectiveness of complex physiotherapy, i.e. the combination therapy (TENS + UD) and postisometric relaxation. However, they claim at the same time that the effectiveness of the therapy has to be verified by multicenter research carried out on a large population.

\section{CONCLUSIONS}

1. A tailored therapeutic program including postisometric relaxation and combination therapy improves mobility in all motion planes and is an effective method for controlling pain in patients with hip osteoarthritis.

2. Systematically conducted therapy has a beneficial effect in reducing the frequency of pain, which is manifested by a limitation of pharmacotherapy.

3. In further studies it must be verified which element of the therapy procedure (postisometric relaxation or the combination therapy) is effective in patients with limited mobility and concomitant pain.

\section{LIMITATION}

The authors of the study are aware of shortcomings regarding the research and its results. The weakness obviously lies in a lack of verification of the results with a control group which would determine the positive therapeutic factor. At this stage of the study it is still not known. This leads the authors to continue their research in order to verify the effectiveness of the therapeutic procedure.

\section{REFERENCES}

[1] Superio-Cabuslay E, Ward MM, Lorig KR. Patient education interventions in osteoarthritis and rheumatoid arthritis: a meta-analytic comparison with nonsteroidal anti-inflammatory drug treatment. Arthritis Care Res. 1996;9:292-301.

[2] Hunter DJ, Arden N, Conaghan PG, et al. Definition of osteoarthritis on MRI: results of a Delphi exercise. Osteoarthritis Cartilage. 2011;19(8):963-969.

[3] Czyzewska A, Glinkowski W, Walesiak K, Krawczak K, Cabaj D, Gorecki A. Effects of preoperative physiotherapy in hip osteoarthritis patients awaiting total hip replacement. Arch Med Sci. 2014;10(5):985-991.

[4] Marciniak W, Szulc A. Wiktora Degi Ortopedia i rehabilitacja [Orthopedics and rehabilitation]. Vol. 2. Warszawa: Wydawnictwo Lekarskie PZWL; 2006. Polish.

[5] American College of Rheumatology Subcommittee on Osteoarthritis Guidelines. Recommendations for the medical management of hip osteoarthritis and knee: 2000 update. Arthritis Rheumatism. 2000;43(9):19051915.

[6] Abbott JH, Robertson MC, McKenzie JE, Baxter GD, Theis JC, Campbell AJ. and the MOA team. Exercise therapy, manual therapy, or both, for hip osteoarthritis or knee: a factorial randomized controlled trial protocol. Trials. 2009;10:11 doi:10.1186/1745-6215-10-11.

[7] Angst F, Aeschlimann A, Steiner W, Stucki G. Responsiveness of the WOMAC osteoarthritis index as compared with the SF-36 in patients with osteoarthritis of the leg undergoing a comprehensive rehabilitation intervention. Ann Rheum Dis. 2001; 60(9): 834-840.

[8] Hinman RS, Bennell KL, Croslley KM, McConnell J. Immediate effects of adhesive tape on pain and disability in individuals with knee osteoarthritis. Rheumatology. 2003;42(7):865-869. 
[9] American GeriatricsSociety Panelon Persistent Pain in Older Persons: The management of persistent pain on older persons. J Am Geriatr Soc. 2002;50:205-224.

[10] Hoeksma HL, Dekker J, Ronday HK, et al. Comparison of manual therapy and exercise therapy in osteoarthritis of the hip: a randomized clinical trial. Arthritis Rheum. 2004;51(5):722-729.

[11] French HP. Physiotherapy management of osteoarthritis of the hip: a survey of current practice in acute hospitals and private practice in the Republic of Ireland. Physiotherapy. 2007;93(4):253-260.

[12] Van Es PP, Luijsterburg PA, Dekker J, et al. Cost-effectiveness of exercise therapy versus general practitioner care for osteoarthritis of the hip: design of a randomized clinical trial. BMC Musculoskeletal Disord. 2011;12:232-238. doi: 10.1186/1471-2474-12-232.

[13] Ying KN, While A. Pain relief in osteoarthritis and rheumatoid arthritis: TENS. Br J Community Nurs. 2007;12 (8):364-371.

[14] Certin N, Aytar A, Atalay A, Akman MN. Comparing hot pack, short-wave diathermy, ultrasound, and TENS on isokinetic strength, pain, and functional status of woman with osteoarthritic knees: a single-blind, randomized, controlled trial. J Phys Med Rehabil. 2008;87:443-451.

[15] Nonaka H, Mita K, Watakabe M, et al. Age-related changes in the interactive mobility of the hip and knee joints: a geometrical analysis. Gait Posture. 2002;15(3):236-243.

[16] Kerrigan DC, Lee LW, Collins JJ, Riley PO, Lipsitz LA. Reduced hip extension during walking: healthy elderly and fallers versus young adults. Arch Phys Med Rehabil. 2001;82(1):26-30.

[17] Holla JF, van der Leeden M, Roorda LD. Diagnostic accuracy of range of motion measurements in early symptomatic hip and/or knee osteoarthritis. Arthritis Care Res (Hoboken). 2012;64(1):59-65

[18] Brantingham JW, Globe G, Pollard H, Hicks M, Korporaal C, Hoskins W. Manipulative therapy for lower extremity conditions. Expansion of literature review. J Manipulative Physiol Ther. 2009;32(1):53-71.

[19] Gould D, Kelly D, Goldstone L, Gammon J. Examining the validity of pressure ulcer risk assessment scales: developing and using illustrated patient simulations to collect the data information point: Visual Analogue Scale. J Clin Nurs. 2001;10(5):697-706.

[20] Laitinen J. Acupuncture and transcutaneous electrical nerve stimulation in the treatment of chronic sacrolumbalgia and ischialgia. Am J Chin Med. 1976;4(2):169-175.

[21] Russe OA, Gerhardt J. International SFTR method of measuring and recording joint motion ISOM, international standard orthopedic measurements. Bern: Hans Huber Publishers; 1975.

[22] Rakowski A. Kregoslup w stresie [Spine under stress]. Gdansk: Gdanskie Wydawnictwo Psychologiczne; 2005. Polish.

[23] Bennell KL, Egerton T, Pua Y, et al. Efficacy of multimodal physiotherapy treatment program for hip osteoarthritis: a randomized placebo-controlled trial protocol. BMC Musculoskeletal Disord. 2010;11:238 doi:10.1186/1471-2474-11-238.

[24] Kamioka H, Tsutani K, Mutoh Y, et al. A systematic review of nonrandomized controlled trials on the curative effects of aquatic exercise. Int J Gen Med. 2011;4:239-260.

[25] Murphy SL, Lyden AK, Clary M, et al. Activity pacing for osteoarthritis symptom management: study design and methodology of a randomized trial testing a tailored clinical approach using accelerometers for veterans and non-veterans. BMC Musculoskeletal Disord. 2011;12:177 doi: 10.1186/1471-2474-12-177.

[26] Taradaj J, Feliksik M, Franek A, Blaszczak E. Terapia skojarzona (TENS + UD) w leczeniu bolow krzyza [Combination therapy (TENS + UD) in treating lumbar pains]. Rehabil Prakt. 2008;4:38-39. Polish.

[27] Khadilkar A, Milne S, Brosseau L, et al. Transcutaneous electrical nerve stimulation for the treatment of chronic low back pain: a systematic review. Spine. 2005;30(23):2657-2666.

[28] French HP, Cusack T, Brennan A, et al. Exercise and manual physiotherapy arthritis research trial (EMPART): a multicentre randomized controlled trial. BMC Musculoskeletal Disord. 2009;10:9 doi:10.1186/1471 2474-10-9. 